\title{
O IMPACTO DA PRÁTICA DA RESPONSABILIDADE SOCIAL NA ESTRATÉGIA DO NEGÓCIO
}

\section{ARTIGO ORIGINAL}

SANCHES, Vander Lúcio ${ }^{1}$

MELO, Alan Da Silva ${ }^{2}$

PINHEIRO, Igor Gonçalves ${ }^{3}$

LEITE, Isadora Clotilde De Siqueira ${ }^{4}$

BICALHO, Rachel Ferreira Sette ${ }^{5}$

CANDIDO, Marlucio ${ }^{6}$

NASCIMENTO, Kathleen Garcia ${ }^{7}$

SANCHES, Vander Lúcio. Et al. 0 impacto da prática da responsabilidade social na estratégia do negócio. Revista Científica Multidisciplinar Núcleo do Conhecimento. Ano 03, Ed. 10, Vol. 05, pp. 131-153 Outubro de 2018. ISSN:24480959

${ }^{1}$ Doutorando-Professor Universitário-UFP: Universidade Fernando Pessoa - Porto Portugal Una, Pitágoras, FEAD, UFMG.

2 Funcionário púbico, Contador- Pós-Graduado-UFMG.

${ }^{3}$ Graduado, administração-Conservador.

${ }^{4}$ Pós- Graduando-Administradora-Colégio Clotilde Leite.

${ }^{5}$ Mestra-Professora Universitária- FEAD.

${ }^{6}$ Mestre-Coordenador De Curso-Pitágoras.

${ }^{7}$ Mestra-Professora-FEAD. 


\section{RESUMO}

Com o crescimento da economia, e o avanço da tecnologia, as empresas tornaramse agentes de grande influência sobre a sociedade, durante muito tempo com a política econômica capitalista ainda utilizada no mundo contemporâneo. Quanto maior a corporação, maior o seu poder de impacto sobre a sociedade e consequentemente, mais exposta está ao julgamento da sociedade, o que exige que as organizações repensem suas estratégias para garantir sua sobrevivência e se manter competitiva no mercado. O presente artigo tem como objetivo identificar como a pratica da Responsabilidade Social pode impactar na estratégia do negócio. Para a análise dos dados utilizou-se a abordagem qualitativa. Quanto aos fins a pesquisa foi descritiva e bibliográfica. Já quanto aos meios foi realizado um estudo de caso. E como instrumentos de coleta de dados, foi utilizado entrevista semiestruturada com a Analista de Recursos Humanos de uma empresa do ramo laboratorial, que obteve também a percepção de outros dirigentes a respeito do tema que se relacionava as perguntas. Foi utilizado também, informações pertinentes ao assunto disponíveis no site da empresa, para o desenvolvimento da análise. A Estratégia é fundamental para a sobrevivência de uma organização e a Responsabilidade Social é um fator influente na estratégia do negócio.

Palavras-Chave: Responsabilidade Social, Estratégia, Diferencial competitivo

\section{INTRODUÇÃO}

Debates e pesquisas relacionadas a responsabilidade social são atividades recentes, o que não significa que o termo seja recente. Diversos autores e estudiosos, tem dedicado certa atenção em investigar o tema Responsabilidade Social, com o intuito de definir seu conceito de forma mais precisa.

A reflexão sobre responsabilidade social por parte das organizações, apesar de ter ganhado força recentemente, já vem sendo explorada desde o início do século XX, onde há registros de manifestações a favor deste comportamento (ALENCASTRO, 2012). Nas últimas décadas as empresas se mostraram mais preocupadas com as 
obrigações sociais e tem dado mais atenção a respeito. Recomendações de que as empresas deveriam dispor parte de seus recursos para ações em prol da sociedade nem sempre foram bem aceitas (MONTANA; CHARNOV, 2001).

Com a globalização, e o constante avanço da tecnologia, a complexidade dos negócios tem crescido cada vez mais, o que tem contribuído para o aumento da competitividade entre as empresas, de onde vem a necessidade de investimentos em processos de gestão que aumentem os diferenciais competitivos (ABNT NBR ISO 26000:2010). Quando se fala em competitividade, logo vem em mente o termo estratégia, que segundo Montgomery e Porter (1998) é um plano de ação para competir com as demais empresas, para definir este plano é preciso saber quem somos e o que temos no momento para competir. Os competidores que mais podem nos atingir são os mais semelhantes a nós. A diferença entre os competidores está de onde provem a sua vantagem competitiva.

Kaplan e Norton (2004) indiretamente relacionam a estratégia com a responsabilidade social quando sustentam que a estratégia descreve como a empresa propõe-se a gerar valor para os acionistas, clientes e cidadãos. Esta geração de valor para a sociedade, pode ser considerada um diferencial competitivo seguindo a linha de pensamento de Maluf e Sampaio (2010) quando afirmam que o ambiente legal, ético e responsável da empresa pode ser explorado pelo marketing como meio de promover a imagem da empresa.

Diante do exposto, esta pesquisa buscou responder a seguinte pergunta: Como a prática da Responsabilidade Social impacta na estratégia do negócio?

Neste contexto, esta pesquisa tem objetivo de conceituar os termos "Responsabilidade Social" e "Estratégia", analisar como as duas práticas se relacionam, e identificar os métodos de integração da responsabilidade social na gestão de maneira estratégica para o negócio e seus respectivos aspectos em uma empresa. 


\section{DESENVOLVIMENTO}

\subsection{ORIGEM E CONCEITOS SOBRE ESTRATÉGIA}

A palavra Estratégia, hoje muito empregada no meio empresarial, tem sua origem na área militar. Diversos autores como Sun Tzu, com seu livro A Arte da Guerra, Maquiavel, com seu livro O príncipe, e Clausewitz, no seu livro Da Guerra, se destacam ao utilizarem de histórias e aprendizagem em situações diplomáticas e militares como referência para ações futuras. $O$ conceito de estratégia militar teve forte influência para os autores de bibliografia sobre estratégia, principalmente nos estudos iniciais de estratégia e, de certa forma até hoje. Conceitos como concorrência, competição e até mesmo inimigo ou guerra aparecem com frequência em diversas bibliografias relacionadas a estratégia.

Segundo Porter (1998), Andrews e Christensen identificaram no início dos anos 60, época onde a gerencia estava voltada para áreas especificas como marketing, produção e finanças, a necessidade de um modelo mais amplo de se pensar a empresa, foi onde articularam o conceito de estratégia.

Ansoff (1977) considerado o pai da administração estratégica, descreve estratégia como um conjunto de regras de tomada de decisão para orientação do comportamento de uma organização diante de situações futuras com objetivos predeterminados. Também aponta seis categorias estratégicas, e afirma que cada empresa se enquadra a uma delas, desde que suas ações estejam direcionadas a determinados objetivos. As categorias expostas por Ansoff são as seguintes:

1.Maximo rendimento atual. A estratégia deste tipo consiste em extrair o máximo de seu ativo, e elevando ao máximo a liquidez de caixa, objetivando a sobrevivência para continuar a produzir renda.

2.Ganho de Capital. É uma estratégia que busca obter o lucro a curto prazo, tratando com desprezo os objetivos a longo prazo, com intuito de estabelecer uma imagem 
pública de empresa em crescimento vertiginoso. Está entre as principais características de empresas que tem intenção de atrair capital ou atenção.

3.Liquidez de Patrimônio. A estratégia deste tipo consiste em atrair compradores (sócios), procurando demonstrar flexibilidade patrimonial. É típica de empresas que querem fundir a outras empresas ou abrir o capital, as famosas "SA" (Sociedade Anônima).

4.Responsabilidade Social. É uma estratégia onde os dirigentes atentam para questões comunitárias e/ou ecológicas às quais estão designados seus interesses.

5.Filantropia. Este tipo de estratégia dispõe parte de seus recursos para objetivos não econômicos ou instituições não lucrativas.

6.Atitude para com os riscos. É uma estratégia focada na redução dos riscos do negócio, mesmo que se obtenha menores lucros.

Os quatro conceitos básicos sobre estratégia segundo Whittington, são o racional, fatalista, pragmático e relativista, que tem implicações diferentes no que diz respeito a "realizar a estratégia".

A abordagem Clássica, a mais antiga e ainda amais influente, conta com os métodos de planejamento racional predominantes nos livros. A seguir, abordagem Evolucionista se apoia na metáfora fatalista da evolução biológica, mas substitui a disciplina do mercado pela lei da selva. Os Processualistas dão ênfase a natureza imperfeita da vida humana, e acomodam pragmaticamente a estratégia ao processo falível tanto das organizações quanto dos mercados. Por fim, a abordagem Sistêmica é relativista, considerando os fins e os meios da estratégia como ligados, sem escapatória, as culturas e aos poderes dos sistemas sociais dos locais onde ela se desenvolve. (WHITTINGTON, 2002, p. 2).

Segundo Mintzberg (2000), estratégia é um procedimento a ser seguido durante um certo período de tempo, onde deve haver regularidade no comportamento do grupo, 
assim como focalizar os esforços, de modo a obter maior coerência entre as ações programadas e as intervenções realizadas. A estratégia tem como finalidade direcionar as ações de acordo com os objetivos da organização. Mintzberg define a estratégia como "5 P's" (Plan, Pattern, Position, Perspective, Ploy), e também apresenta cinco tipos de estratégia, são elas: pretendidas, deliberadas, realizadas, não-realizadas e emergentes, que podem ser diferenciadas a partir das mudanças ambientais, ou seja, das incertezas internas e externas à empresa, que favorecem o surgimento e/ou a utilização de uma determinada estratégia em detrimento de outra.

Os tipos de estratégia apresentados por Mintzberg (2000, p. 19) podem ser visualizados na figura:

Figura - Estratégias deliberadas e emergentes

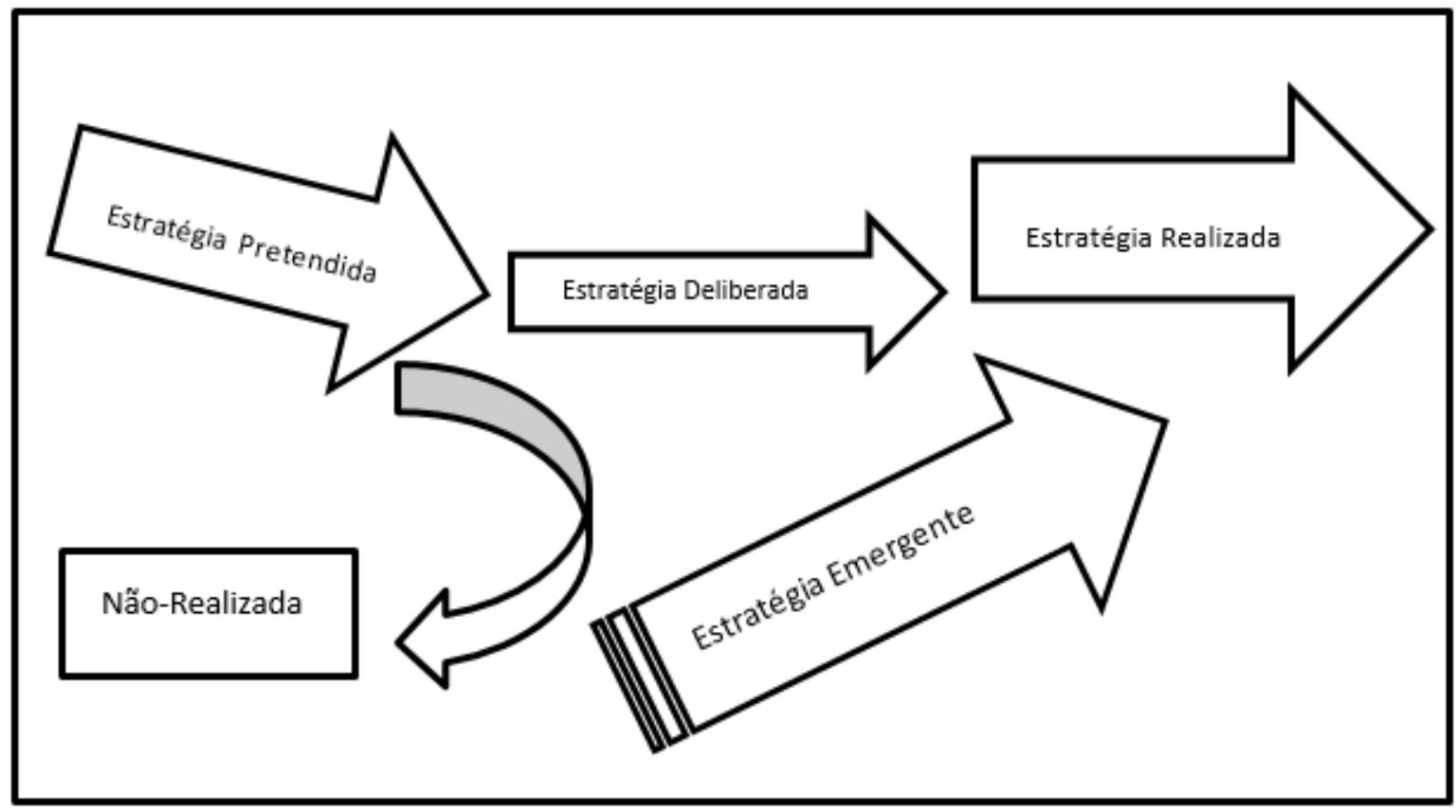

Fonte: adaptado de Mintzberg (2000, p. 19)

Estratégia como plano (primeiro $\mathrm{P}$, Plan), significa aquilo que foi pretendido, é a estratégia definida em conformidade com o plano para o futuro. As estratégias deliberadas são aquilo que se pretendeu e foi realizado e as não realizadas são as estratégias pretendidas que não obtiveram sucesso na realização. Já as estratégias 
emergentes, são aquelas onde ocorre algo inesperado, e a organização tem de se adaptar ao novo cenário, é quando o realizado não é pretendido. A convergência das estratégias deliberadas e das estratégias emergentes é a estratégia como padrão (segundo $\mathrm{P}, \mathrm{Pattern}$ ), que é a estratégia efetivamente realizada. Já a estratégia como posição (terceiro $\mathrm{P}$, Position) é como se posiciona determinados produtos em determinados mercados. E a estratégia como perspectiva (quarto $P$, Perspective) é a forma com base nos fundamentos da organização de fazer as coisas. E por fim, o (quinto P), Ploy, é a Estratégia como truque, isto é, uma manobra específica para sobressair, levar vantagem diante do concorrente. MINTZBERG (2000)

Já Kaplan e Norton os criadores do BSC, conceituam como:

A escolha dos segmentos de mercado e clientes que as unidades de negócios pretendem servir, identificando os processos internos críticos nos quais a unidade deve atingir a excelência para concretizar suas propostas de valor aos clientes dos segmentos alvo, e selecionando as capacidades individuais e organizacionais necessárias para atingir os objetivos internos, dos clientes e financeiros. (KAPLAN; NORTON, 1997, p.38 apud FARIAS, 2007, p.15).

Kaplan e Norton (2004), também dizem que a estratégia é uma das etapas de um processo contínuo que movimenta toda a organização desde a declaração de missão até o operacional, e deve descrever como a empresa pretende criar valor para seus acionistas, clientes e cidadãos.

A missão da organização fornece o ponto de partida, ao definir por que a organização existe ou como a unidade de negócios se enquadra dentro das fronteiras da arquitetura organizacional total. A missão e os valores essenciais que a acompanham mantem-se bastante estáveis no tempo. A visão da organização pinta um quadro do futuro que ilumina a trajetória da organização e ajuda os indivíduos a compreenderem por que e como devem apoiar a organização. Além disso, a visão coloca a organização em movimento, tirando-a da estática da missão e dos valores essenciais 
para a dinâmica da estratégia, a etapa seguinte do processo continuo. A estratégia desenvolve-se e evolui com o tempo, para atender as condições em mutação impostas pelo ambiente externo e pelas competências internas. (KAPLAN; NORTON, 2004, p.38)

Porter (1999), define "estratégia" como a busca deliberada de um plano de ação visando otimizar a vantagem competitiva de uma empresa. E concorda com Kaplan e Norton (1997, p.38), ao afirmar que: a estratégia da empresa define a configuração específica de suas atividades, e as diferentes posições estratégicas envolvem atividades sob medida para a produção de determinada variedade de produtos e serviços, para atender às necessidades de um determinado grupo de clientes.

Confrontando às teorias de Porter, Barney e Hesterly (2007) apud Oliveira (2014) ressaltam que:

apesar de também, considerarem que a estratégia de uma empresa deve servir para indicá-la o melhor caminho para obtenção de vantagem competitiva frente a um mercado que vive um constante e acelerado processo de evolução, entendem que as mesmas devem decorrer dos recursos diferenciados que essas empresas têm, e não das estruturas em que se inserem (como considera Porter). (BARNEY; HESTERLY, 2007, apud OLIVEIRA, 2014, p.22)

Percebe-se que a diversidade de conceitos sobre estratégia no decorrer do tempo, evidencia que sua definição sofreu variações de acordo com a finalidade pretendida. Mais recentemente, sem fugir da base dos conceitos anteriores tem-se a visão de Chiavenato (2009), para quem a estratégia é sobretudo um curso de ação escolhido pela organização a partir do princípio de que uma posição futura em um outro cenário, poderá oferecer ganhos e vantagens em relação a situação atual.

Entrando em um senso comum referente ao que dizem os autores citados, pode se dizer que Estratégia é um plano de ação, um direcionamento, onde é feito uma previsão do cenário futuro. É uma escolha que envolve toda a organização e consiste 
em selecionar, dentre várias hipóteses existentes, qual deve ser escolhida como base para as tomadas de decisões. A estratégia pode ser pré-concebida, quando é baseada em modelos anteriormente estabelecidos, como também assumir a forma de uma estratégia emergente, quando surge naturalmente no decorrer dos processos. É também fortemente influente na escolha da base física ou uma situação vantajosa. É notável que sobre estratégia se tem tantos livros escritos quanto definições.

\subsection{PLANEJAMENTO ESTRATÉGICO}

Enquanto a estratégia da empresa trata do "como fazer" e como obter os resultados, por ser curso da ação organizacional, definido por meio de planos, o planejamento estratégico trata do "que fazer", em consonância com as necessidades das unidades organizacionais, envolvendo os planos traçados para conduzir eficazmente a organização nos seus ambientes. No ambiente externo, ou macro-ambiente, a avaliação organizacional apresenta-se através da análise das oportunidades e de ameaças. Wright (2000, p. 47) afirma que o setor em que a organização está inserida pode impor barreiras ou obstáculos, que são as ameaças, ou oferecer benefícios, que são as oportunidades:

A estrutura de um setor influencia a intensidade da competição entre as empresas que dele fazem parte, impondo algumas restrições em suas operações e oferecendo várias oportunidades para que as empresas bem administradas obtenham vantagens sobre suas concorrentes (WRIGHT, 2000, p. 47).

À definição da estratégia segue-se a fase de implementação, que segundo Lobato (2003), depende de dois fatores: o emprego da ferramenta adequada e a receptividade das pessoas da organização. Após esta fase, a estratégia deve ser controlada, a fim de identificar se o que foi planejado foi eficazmente atingido, com a adoção de medidas corretivas ou de continuidade.

Por fim, para Oliveira (1991, p. 26), a finalidade das estratégias empresariais é "estabelecer quais serão os caminhos, os cursos, os programas de ação que devem 
ser seguidos para alcançar os objetivos estabelecidos pela empresa". Para estabelecer o referido caminho, torna-se necessário delimitar alguns elementos, como metas, o direcionamento e os objetivos, por exemplo. Tal delimitação é realizada no processo de planejamento estratégico.

Diante do exposto, compreende-se que avaliação e controle são essenciais para obter os resultados esperados e para que a organização mantenha se competitiva.

\subsection{HISTÓRICO E CONCEITOS DA RESPONSABILIDADE SOCIAL}

A teoria sobre Responsabilidade Social surgiu na década de 1950, Bowen (1957) foi um dos pioneiros da ideia, tomou como base a concepção de que as empresas são núcleos de poder e decisão, e que todas as ações por estas decididas impactam na vida da sociedade em diversos pontos, foi de onde questionou quais responsabilidades a sociedade anseia receber das empresas, e defendeu a ideia de que as empresas devem atentar-se mais em compreender de forma abrangente seu impacto social, e que o desempenho social e ético deve ser analisado por meio de auditorias e devem ainda ser incorporados a gestão da organização. (BOWEN apud BERTONCELLO; JUNIOR, 2007)

A apreensão daqueles que se dedicavam à pesquisa do tema, era a imensa autonomia das organizações e o poder que estas representavam sobre a sociedade, sem mensurar suas responsabilidades pelas consequências possivelmente negativas das atividades que desempenhavam, como por exemplo, a degradação ambiental, a exploração do trabalho, o abuso econômico e a concorrência desleal. Em resposta aos impactos causados e buscando amenizar os aspectos negativos de sua atuação em sociedade, os empresários passaram a se envolver com atividades sociais com o intuito de beneficiar a comunidade, pode se considerar tal ato mais como uma retribuição pelo dano causado do que como um benefício, é obrigação moral. (BORGER, 2001)

Já Torres (2003) citado por Alencastro (2013) aponta que um dos fatores que influenciou as empresas a adotarem ações de responsabilidade social foi a crise do 
Welfare State (Estado de bem-estar Social) na metade da década de 1970. Torres também cita a crise econômica e o crescimento do desemprego que atingiram a Europa na década de 1980 como outro contribuinte para que as empresas passassem a olhar para a sociedade com outros olhos.

Nos dias atuais percebe-se a grande movimentação do comportamento dos consumidores no sentido de pressionar as empresas a rever seus princípios éticos e morais. Tem ganhado cada vez mais força a tendência do consumidor em optar por empresas que não estão focadas apenas para a produção e o lucro. Esta exigência faz com que as empresas busquem aderir por atitudes mais responsáveis, fato que pode contribuir para que sobressaiam sobre as concorrentes, já que a responsabilidade social passou a ser considerado um diferencial competitivo, e desta maneira as empresas também atuam a favor da sociedade. (ALENCASTRO, 2013)

Para a escola da economia clássica, a única obrigação da empresa é gerar lucro para seus acionistas dentro dos limites legais. O maior defensor do ponto de vista clássico foi o ganhador do Prêmio Nobel, o economista Milton Friedman, citados por Montana e Charnov (1998), para quem a responsabilidade primária de uma organização consiste em dirigir os negócios com a finalidade de proteger os interesses dos acionistas.

Quando se fala em Responsabilidade Social, está se tratando de ética, de relação socialmente responsável por parte das organizações diante de suas ações, suas políticas, suas atitudes para com todos os agentes envolvidos.

A Responsabilidade Empresarial começa com a avaliação da importância e do poder das empresas. Elas são detentoras de meios de influencia muito grandes, o que implica ter muita responsabilidade. Toda empresa é uma força transformadora poderosa, é um elemento de criação e exerce grande ascendência na formação de ideias, de valores, nos impactos concretos na vida das pessoas, das comunidades, da sociedade em geral. (ESTEVES, 2000, p.40) 
Kreitlon (2004), aponta três abordagens da Responsabilidade Social: normativa, contratual e estratégica.

A abordagem normativa, baseia-se na ideia de que a empresa e suas atividades estão sujeitas ao julgamento ético. Segundo esta abordagem, a responsabilidade social da empresa deriva justamente de sua responsabilidade ética, ou seja, a mesma deve agir de modo socialmente responsável já que isto é o correto, e é seu dever moral cumprilo. Para que determinada ação possa ser considerada "ética", presume-se que tenha a existência de um sujeito livre (dispõe da oportunidade de escolha), consciente (capaz de deliberação), e responsável (determinante para a ocorrência do ato). Em conformidade com a maioria dos autores que partilham deste ponto de vista, o ato corporativo não pode ser reduzido ao ato individual, visto ser a empresa uma coletividade que transcende a soma dos sujeitos que a compõe. Por outro lado, a empresa possui finalidades, objetivos e um processo decisório próprios, distintos daqueles dos individuais a quem cabe implementa-los. As principais características desta escola são: sua posição precursora dos estudos nessa área, sua forte base filosófica, e seu viés predominantemente normativo.

Já a abordagem contratual tem como base três grandes pressupostos teóricos: a) empresa e sociedade são parte de um mesmo sistema, e estão em constante interação; b) ambas estão ligadas entre si por um contrato social; c) a empresa está sujeita ao controle por parte da sociedade.

Quanto maior o poder de uma organização, maior é a quantidade de stakeholders, o que consequentemente eleva o grau de impactos sociais que possam ser causados, o que aumenta a pressão para que as empresas atuem de modo responsável. O poder da empresa quando mal utilizado, traz como consequência para a mesma, a perda de legitimidade, reduzindo ou até mesmo retirando o seu poder diante da sociedade, em decorrência de novas legislações impostas pelo governo. A abordagem contratual ressalta que, a empresa deve desempenhar determinadas funções junto à sociedade, e que sua legitimidade depende do correto cumprimento dessas funções. 
Mais recente tem-se a abordagem estratégica, que procura por sua vez proporcionar ferramentas práticas de gestão, apropriadas para a melhoria do desempenho ético e social da organização, baseando se na ideia de que é bom para a sociedade, também é bom para a empresa e vice-versa.

Esta perspectiva, que também pode ser chamada de utilitária ou instrumental, defende a ideia de que, a médio e longo prazos, o que é bom para a sociedade é bom para a empresa - sugerindo, de maneira implícita e correlata, que aquilo que é bom para a empresa também é para a sociedade, postulado fundamental das teses econômicas neoclássicas. (KREITLON,2004, p.9)

Segundo Jones (1996) apud Kreitlon (2004), as justificativas para reponsabilidade social que expõe esta abordagem se sustenta em três argumentos, todos de natureza utilitária: a) a empresa pode se beneficiar das oportunidades de mercado consequentes de mudanças nos valores sociais, desde que se antecipe as mudanças; b) o comportamento socialmente responsável pode ser considerado uma vantagem competitiva; c) uma atitude arrojada permite antecipar-se a mudanças legislativas, ou até mesmo evitá-las.

Os dois primeiros argumentos são basicamente estratégias de marketing, e, assim como o terceiro, fazem analogia a visão neoclássica dos objetivos organizacionais, segundo a qual a única função legítima da empresa é perseguir seus próprios interesses que são o crescimento e lucratividade, o que justificam sua existência. É com base nestes argumentos, que inúmeros estudiosos justificam esta abordagem está intrinsicamente envolvida em diversos estudos que tem como intenção correlacionar a Responsabilidade Social com a lucratividade das organizações. (KREITLON,2004)

Seguindo a linha de pensamento de JONES (1996) com a relação à abordagem estratégica da responsabilidade social, para que a estratégia de diferenciação possa ser implementada é importante que a empresa leve em consideração algumas características inerentes a essa formulação estratégica, é necessário reservar 
recursos para investimentos em pesquisa e desenvolvimento, e a área de $P \& D$ da empresa deve integrar-se com a área de marketing. Isso é crucial, pois, se não existir essa integração, o esforço de desenvolvimento de novos produtos, imagem de marca, sistemas de atendimento e demais atividades, como por exemplo, projetos de Responsabilidade Social, podem estar fora de sintonia com o que o mercado quer e percebe, gerando assim uma lacuna entre o custo da estratégia de diferenciação e o valor agregado por ela. (GHEMAWAT, 2000)

No mesmo contexto Montana \& Charnov (2001) concordam em partes no que se refere as abordagens apontadas por Kreitlon (2004), ao expor o envolvimento da organização com ações de responsabilidade social em três níveis: (1) Abordagem da obrigação social - parte do pressuposto que a finalidade da organização é a produção e geração de lucro para os acionistas, resumidamente a sua razão de existência é o seu próprio desenvolvimento econômico, no entanto a empresa deve arcar somente com as ações sociais mínimas exigidas por lei. (2) Abordagem da responsabilidade social - compreende que as questões sociais não fazem parte das metas econômicas da empresa, mas que a empresa deve destinar recursos para que se realize estas ações sociais. (3) Abordagem da sensibilidade social - entende-se que a empresa além de possuir metas sociais e econômicas, tem de se antecipar aos problemas sociais futuros já com o intuito de responder a esses problemas.

\subsection{ARGUMENTOS PRÓS E CONTRAS A RESPONSABILIDADE SOCIAL}

De acordo com Pinto (2002) existem forças que estimulam e orientam o processo de adaptação das organizações a ideia de responsabilidade social. Algumas das organizações que desenvolvem iniciativas estratégicas nessa área são: Associação dos Dirigentes Cristãos de Empresas do Brasil (ACDE), Conselho Empresarial Brasileiro para o Desenvolvimento Sustentável (CEBDS), Fundação Instituto de Desenvolvimento Empresarial e Social (Fides), Grupo de Institutos, Fundações e Empresas (Gife) e Instituto Ethos. 
Conforme afirma o Instituto Ethos, as organizações ao adotarem um comportamento socialmente responsável, são poderosos agentes de mudança e com apoio do estado e da sociedade civil, podem contribuir para um mundo melhor. Este comportamento é caracterizado por uma postura ética frente a suas ações e relações com os stakeholders.

Muitos acusaram Friedman e seus seguidores de não dar a devida importância as causas sociais. Em contrapartida, Friedman e seus seguidores tem como sustentação a ideia de que a empresa não deve assumir responsabilidade social de forma direta. A afirmativa se sustenta em premissas práticas e teóricas citadas por Montana e Charnov são:

\subsection{ARGUMENTOS TEÓRICOS CONTRA A RESPONSABILIDADE SOCIAL}

1. Esta é a função principal do governo; ligar o setor empresarial ao governo criara uma força poderosa demais na sociedade.

2. O setor empresarial precisa medir desempenho, e os programas de ação social frequentemente não conseguem medir os níveis de sucesso. Muitas vezes, há um conflito inerente entre a maneira como uma empresa opera e a maneira como os programas sociais funcionam.

3. A função de uma empresa é otimizar o lucro. Assim, exigir que parte de seus recursos seja destinada a programas de ação social viola essa meta empresarial, já que reduz os lucros.

4. Não existe nenhuma razão para se supor que os líderes empresariais tenham habilidade para determinar o que e de interesse social. Cientistas sociais e administradores do governo frequentemente não conseguem entrar em um acordo sobre as metas de interesse social; então, como supor que líderes empresariais podem fazer um trabalho melhor em definir o interesse social? 


\subsection{ARGUMENTOS PRÁTICOS CONTRA A RESPONSABILIDADE SOCIAL}

1. Gerentes tem uma responsabilidade fiduciária para com os acionistas de otimizar seu patrimônio líquido, e o uso de fundos da empresa para a realização de metas sociais é passível de ser um a violação dessa responsabilidade, podendo assim ser ilegal.

2. O custo de programas sociais seria um peso para as empresas e teria de ser repassado aos consumidores na forma de aumento nos preços.

3. O público quer que o governo desenvolva programas sociais, mas existe pouco apoio para que as empresas tenham esses programas.

4. Não existe nenhuma razão para se supor eu os líderes empresariais tenham a habilidade necessária para atingir as metas de interesse social.

Friedman e seus muitos seguidores apud Montana; Charnov (2001) argumentam que a finalidade da empresa é a busca do lucro dentro do que é permitido pela legislação. Reforçando seus argumentos ainda ressaltam que uma empresa lucrativa, sucessivamente traz benefícios a sociedade ao gerar empregos, e também melhorias no bem-estar social, através dos respectivos pagamentos de impostos. Ainda conclui que a empresa que concentra seus recursos em suas atividades fins, utiliza seus recursos com maior eficiência e eficácia aumentando sua competitividade.

Contrapondo os argumentos de Friedman, Keith Davis apud Montana; Charnov (2001) defende que haja responsabilidade social nas empresas. Ele argumenta que a responsabilidade social anda de mãos dadas com o poder social, e já que a empresa é a maior potência no mundo contemporâneo, ela tem a obrigação de assumir uma responsabilidade social proporcional a seus impactos na sociedade. Por sua vez, a sociedade, que deu esse poder as empresas, pode chamar a empresa para prestar contas pelo uso desse poder. Davis também afirma que a empresa precisa estar aberta aos problemas sociais e que a sociedade deve valorizar os esforços na área 
da responsabilidade social. Ser socialmente responsável tem seu custo, mas o mesmo não deve ser necessariamente considerado uma barreira para a inclusão da responsabilidade na empresa, já que a empresa tem meios de repassar esse custo aos consumidores. De forma ainda mais revolucionaria, assim como Kreitlon (2004) Davis concorda que o que é bom para a sociedade também é bom para empresa ao afirmar que a empresa deve se sensibilizar em ajudar a resolver problemas sociais, mesmo que a própria não esteja diretamente envolvida. Os argumentos de Davis e de seus seguidores, conforme cita Montana e Charnov a favor da responsabilidade social das empresas também são de natureza teórica e pratica:

\subsection{ARGUMENTOS TEÓRICOS A FAVOR DA RESPONSABILIDADE SOCIAL}

1. É do interesse da empresa melhorar a comunidade na qual estão localizadas e onde fazem seus negócios. Melhorias na comunidade implicam benefícios a empresa.

2. Programas sociais podem impedir que pequenos problemas se tornem grandes, 0 que trará benefícios tanto para a sociedade como para a empresa.

3. Ser socialmente responsável é a coisa ética ou "correta" a se fazer.

4. Demonstrar sensibilidade com relação a assuntos sociais ajudará a impedir a intervenção do governo nas empresas.

5. O sistema de valores mais aceito, como a tradição judaico-cristã, encoraja vigorosamente os atos de caridade e a preocupação social.

\subsection{ARGUMENTOS PRÁTICOS A FAVOR DA RESPONSABILIDADE SOCIAL}

1. Ações que demonstram sensibilidade social podem, na verdade, ser lucrativas para a empresa.

2. Ser socialmente responsável melhora a imagem pública da empresa. 
3. Se a empresa for socialmente responsável por conta própria, a opinião pública ou o governo exigirão que ela seja.

4. Pode ser bom para os acionistas, já que tais ações merecerão a aprovação publica farão com que a empresa seja vista por analista financeiros profissionais como pouco propensa a críticas sociais e aumentarão a cotação na bolsa de valores.

\section{METODOLOGIA}

Os recursos técnicos de pesquisa utilizados no presente artigo foram respectivamente a pesquisa bibliográfica e entrevista. A pesquisa bibliográfica foi complementada com a entrevista dentro da empresa apresentada. Pádua (2009, p. 55) quanto a pesquisa bibliográfica, afirma que esta tem como objetivo estabelecer o contato entre o pesquisador e o que já se produziu relacionado ao seu tema de pesquisa.

A coleta de dados se deu com entrevista semiestruturada com a Analista de Recursos Humanos da empresa, de onde se obteve informações e dados que foram analisados e relacionados com os resultados da pesquisa. Segundo Pádua $(2009$, p. 70$)$ as entrevistas "constituem uma técnica alternativa para se coletar dados não documentados, sobre um determinado tema."

Para analisar como a pratica da responsabilidade social impacta na estratégia do negócio, foi realizada uma pesquisa descritiva, obtendo informações e descrevendo sobre o problema em questão. Na pesquisa descritiva, o objeto é estudado em sua totalidade; descreve-se as características da população e estabelece-se relações entre as variáveis. Quanto aos meios, utilizou-se pesquisas bibliográficas e uma entrevista semiestruturada, onde foi organizado um conjunto de questões sobre o tema estudado, permitindo e incentivando a pessoa entrevistada a falar livremente sobre assuntos que foram surgindo como desdobramento do tema principal. 


\section{DISCUSSÃO}

\subsection{ESPECIFICAÇÃO DA EMPRESA}

A empresa entrevistada Hermes Pardini S.A, com sede em Belo Horizonte - MG, foi fundada em 1959, precursora do mercado de Apoio Laboratorial, o Hermes Pardini conta, hoje, com cerca de 5 mil laboratórios parceiros, com os quais está em contato constante, na busca por aprimorar seus serviços a partir do entendimento da realidade e das necessidades dos clientes. Entre os serviços oferecidos por suas unidades próprias, além de análises clínicas, estão: diagnóstico por imagem, vacinas, provas funcionas, criopreservação, genética humana e veterinária. A empresa tem como objetivo assegurar confiança, precisão e rapidez no auxílio diagnóstico e no cuidado com a saúde. Tornando-se uma escolha inequívoca para clientes e profissionais de saúde em apoio diagnóstico.

O fundador da empresa Dr. Hermes Pardini formado em medicina, deu início a organização com a inauguração, em uma pequena sala no centro de Belo Horizonte, do laboratório de análises clínicas que levava o seu nome. Nesta época, o Dr. Hermes Pardini já possuía uma residência em Bioquímica, fazia sua segunda residência, em Patologia Clínica, e dedicava-se, além do seu próprio negócio, ao laboratório da Faculdade de Medicina, que ajudou a criar. A empresa conta hoje com cerca de 4 mil funcionários.

\subsection{DESCRIÇÃO DO RESPONDENTE}

Flaviane Siqueira Guedes, está na empresa a 8 meses, possui o cargo de Analista de Recursos Humanos, é formada em Gestão de Recursos Humanos pela Universidade Pitágoras e atualmente está graduando o $8^{\circ}$ período em psicologia pela mesma universidade. 


\subsection{ANÁLISE DOS DADOS QUALITATIVOS}

Quando perguntada sobre qual seu entendimento sobre estratégia, a analista afirmou que sua percepção a respeito é de que a estratégia é um planejamento a ser seguido com objetivo claramente definido, ela ainda ressalta que é uma forma inteligente de atingir o objetivo.

A percepção da analista está em conformidade com a definição de Mintzberg (2000), para quem a estratégia é um procedimento a ser seguido durante um certo período de tempo, coma a finalidade de direcionar as ações de acordo com os objetivos da organização.

Quando perguntada sobre a existência do departamento de planejamento, planejamento estratégico da empresa, e o envolvimento dos membros da organização na execução do planejamento a respondente informou que a empresa possui sim um departamento especifico para o planejamento, que é o departamento: planejamento de negócios. A empresa possui um planejamento estratégico já definido, o qual não foi declarado, uma das etapas da execução do planejamento estratégico da empresa, foi a recente abertura de capital, o que é uma forma de atrair investidores, contribuindo para a expansão da empresa. O planejamento em primeiro momento envolve o presidente, diretores e gerentes, os quais elaboram e discutem o planejamento, e posteriormente após repassar a toda a equipe os caminhos a serem trilhados e indicalos a melhor maneira para se alcançar os objetivos traçados, controlam toda a execução do planejamento.

A organização age de acordo com a linha de pensamento de Lobato (2003), onde evidencia que a implementação da estratégia tem forte influência do emprego da ferramenta adequada e a receptividade das pessoas da organização. Após esta fase, a estratégia deve ser controlada, a fim de identificar se o que foi planejado foi eficazmente atingido, com a adoção de medidas corretivas ou de continuidade. 
Quanto ao relacionamento entre os colaboradores dentro da organização, o clima organizacional é de harmonia, empatia e cooperação, é um ambiente onde há interação entre as pessoas.

Já a respeito das forças para competir com seus principais concorrentes, entre eles os concorrentes diretos que são: São Marcos, Geraldo Lustosa, e, Axial. Ambos sediados em MG. E os concorrentes das unidades de apoio são os laboratórios: Fleury, Dasa e DB. A analista afirmou que assim como o Hermes Pardini possui forças para competir com seus principais concorrentes, também está entre as maiores empresas do ramo em que atua, é uma empresa de tradição no mercado em que atua a mais de 50 anos, não são todos os laboratórios que são seus concorrentes, tendo em vista que a empresa também presta serviços a outros laboratórios, uma de suas principais forças é a forte cultura organizacional, onde os funcionários vestem a camisa da empresa, a estrutura é voltada para o bem estar dos funcionários, contando com uma biblioteca própria, e o Programa Trilha De Carreira (onde o funcionário enxerga a possibilidade de crescimento e é instruído em como alcançar este objetivo), outro ponto forte é o alto investimento em tecnologia, fator este que fez do Núcleo Técnico Operacional (NTO) da empresa ser o maior da América Latina no ramo laboratorial, além disso, possui parcerias de apoio laboratorial em todo o Brasil.

Quando perguntada sobre a percepção dos gestores quanto a Responsabilidade Social, Flaviane informou que entrando em um consenso entre todas as percepções, pôde se dizer que é uma forma mais humana de gestão de uma organização, onde o olhar não está voltado apenas para a lucratividade da empresa, mas também para a melhoria da sociedade em que está inserida. É um meio de dar oportunidade de crescimento para a sociedade de maneira responsável, e contribuir para a inclusão social. Por outro lado, existe certa resistência de alguns gestores na adesão a alguns projetos. O setor de Desenvolvimento Humano Organizacional busca atuar sempre com sensibilizações e orientações, a fim que tais barreiras sejam quebradas e se tenha o envolvimento e empenho de todos.

A forma de pensar dos gestores, mesmo ainda que se tenha certa resistência por parte de um ou outro em determinados projetos, contrapõe se ao que defende a escola da 
economia clássica, onde a única obrigação da empresa é gerar lucro para seus acionistas dentro dos limites legais. O maior defensor do ponto de vista clássico, Milton Friedman citados por Montana e Charnov (1998), salienta que a responsabilidade primária de uma organização consiste em dirigir os negócios com a finalidade de proteger os interesses dos acionistas.

No que diz respeito a decisão de a empresar aderir a pratica da Responsabilidade Social, foi uma inciativa própria que partiu do setor de Desenvolvimento Humano Organizacional e conta com o incentivo de Dona Carmem, esposa do fundador da empresa o Dr. Hermes Pardini, que tem o pensamento voltado para o âmbito social e faz questão de participar pessoalmente de alguns projetos. Não houve pressão da sociedade e da concorrência, inclusive a prática da responsabilidade social é um diferencial da empresa.

Keith Davis apud Montana; Charnov (2001) defende que haja responsabilidade social nas empresas. Ele argumenta que a responsabilidade social anda de mãos dadas com o poder social, dentre os seus argumentos a favor, afirma que demonstrar sensibilidade com relação a assuntos sociais ajudará a impedir a intervenção do governo nas empresas. Ainda complementa que ser socialmente responsável melhora a imagem pública da empresa. e que a pratica da responsabilidade social pode ser bom para os acionistas, já que tais ações merecerão a aprovação pública e farão com que a empresa seja vista por analista financeiros profissionais como pouco propensa a críticas sociais e aumentarão a cotação na bolsa de valores.

Quando perguntado se havia na empresa uma estrutura adequada para o gerenciamento de projetos de Responsabilidade Social, a analista informou que existe um setor responsável pela Responsabilidade Social da empresa que fica dentro do departamento de Desenvolvimento Humano Organizacional, o que evidência o quanto a empresa se importa com assunto.

Questionado sobre os colaboradores estarem cientes dos projetos em que a empresa atua e do envolvimento dos funcionários com os projetos, obteve se a informação de que a empresa possui a intranet, quadro de avisos, email de comunicação interna, e 
divulgação de atividades inclusive na proteção de tela dos monitores, onde são explicitados também as atividades de cunho social. No final de cada ano a empresa faz distribuição de cestas de natal, onde os funcionários também podem participar. Além de participar das atividades, é permitido que os funcionários indiquem pessoas para participar dos projetos da empresa, tanto como voluntário ou beneficiário, desde que estes se enquadrem dentro dos critérios.

Quanto a relação dos projetos de Responsabilidade Social com a política e estratégia da empresa, os projetos estão diretamente ligados as políticas da companhia e atuam para o alcance das estratégias, uma vez que promovem ações de cunho social voltados a comunidade local, atuando no fortalecimento do relacionamento com a comunidade, colaboradores, setores públicos e privados.

Hoje a empresa atua com diversas ações sociais como o Projeto Sofrimento Mental que é a inclusão de pessoas com esquizofrenia no ambiente de trabalho, Programa Projeção que é um curso de qualificação profissional para jovens de 18 a 20 anos totalmente gratuito que forma 40 jovens por ano, Projeto de Inclusão da Pessoa com Deficiência e Reabilitado, Programa Jovem Aprendiz, Doações a instituições sociais e outros.

O Hermes Pardini também acredita que com os projetos de responsabilidade social, contribui para a inclusão social dos jovens no mercado de trabalho, formando destes, profissionais preparados para o mercado e oferecendo a possibilidade de um futuro melhor, podendo também serem admitidos pelo Hermes Pardini, o que é também considerado como um fator estratégico para a empresa, tendo em vista que os profissionais formados pelo próprio grupo oferecem maior vantagem a empresa. Contribui também para a inclusão e desenvolvimento de pessoas com deficiência e reabilitados no ambiente de trabalho, possibilitando que essas pessoas atuam de forma produtiva em uma reciprocidade de desenvolvimento e crescimento.

Kreitlon (2004), aponta três abordagens da Responsabilidade Social dentre elas a estratégica, que procura por sua vez proporcionar ferramentas práticas de gestão, apropriadas para a melhoria do desempenho ético e social da organização, baseando 
se na ideia de que é bom para a sociedade, também é bom para a empresa e viceversa.

Com a relação à abordagem estratégica da responsabilidade social, Ghemawat (2000), ressalta que, para que a estratégia de diferenciação possa ser implementada é importante que a empresa leve em consideração algumas características inerentes a essa formulação estratégica, é necessário reservar recursos para investimentos em pesquisa e desenvolvimento, e a área de P\&D da empresa deve integrar-se com a área de marketing. Isso é crucial, pois, se não existir essa integração, o esforço de desenvolvimento de novos produtos, imagem de marca, sistemas de atendimento e demais atividades, como por exemplo, projetos de Responsabilidade Social, podem estar fora de sintonia com o que o mercado quer e percebe, gerando assim uma lacuna entre o custo da estratégia de diferenciação e o valor agregado por ela.

De acordo com o que foi informado pela empresa na entrevista, percebe-se que a realidade da empresa condiz com o que argumentam os autores.

Quando perguntado sobre qual a visão os beneficiários e a sociedade têm do Hermes Pardini, a analista informou que a sociedade ver a Hermes Pardini como uma empresa cidadã, uma empresa que não visa apenas o lucro, e se importa com o desenvolvimento da sociedade, o desenvolvimento de pessoas. Já os beneficiários enxergam na Hermes Pardini uma esperança de uma vida melhor, uma esperança de oportunidade, uma empresa que leva motivação para a vida das pessoas.

Sempre que a empresa participa de workshop e eventos socais somos muito abordados por pessoas que se identificam e reforçam a importância do trabalho diferenciado que a empresa promove. Nos processos de seleção de pessoas os candidatos costumam relatar que sabem que a empresa possui trabalhos diferenciais na área social.

Esta visão que a sociedade tem da empresa colocam em evidencia o ambiente legal, ético e responsável da empresa que segundo Maluf e Sampaio (2010) pode ser explorado pelo marketing como meio de promover a imagem da empresa. Jones 
(1996) apud Kreitlon (2004), fortifica esta linha de raciocínio ao afirmar que a empresa pode se beneficiar das oportunidades de mercado consequentes de mudanças nos valores sociais, desde que se antecipe as mudanças.

Quanto aos aspectos provenientes de ser socialmente responsável e seus impactos na estratégia da empresa, não foi mensurado nenhum dado estatístico quantitativo. Já qualitativamente os aspectos resultantes da empresa ser praticamente da Responsabilidade Social, são: Ótimo relacionamento com o Ministério do Trabalho, a boa imagem que a empresa passa para todos os envolvidos com as atividades e projetos da empresa, o que gera um relacionamento saudável com a sociedade, não é ao acaso que em 2009 o Hermes Pardini recebeu o prêmio Ser Humano por dois projetos desenvolvidos: "Universidade Corporativa" e "Gestão de Mudanças". O Hermes Pardini também foi agraciado com o prêmio Top Of Mind Marcas de Sucesso Minas Gerais, recebeu esta premiação durante oito anos consecutivos, de 2005 a 2013 e em 2015/2016. Ser socialmente responsável, pode impactar na estratégia da empresa, limitando a quantidade de fornecedores e empresas que possam ser parceiras, já que tanto para fornecer ou receber apoio do Hermes Pardini, estas empresas devem estar em dia com suas obrigações legais e de acordo com os critérios do Hermes Pardini, mas não tem sido um obstáculo para a empresa que conta hoje com cerca de cinco mil laboratórios parceiros. Os aspectos de ser socialmente responsável traz também impactos positivos, já que como uma das consequências de suas atitudes é o orgulho que os funcionários sentem em trabalhar na Hermes Pardini, fazendo com que a empresa tenha um baixo índice de rotatividade, o que é muito bom para a estratégia da empresa, reduzindo os custos com treinamentos para novos funcionários, e além disso a boa imagem que a empresa passa para a sociedade, faz com que esta indique a empresa para outras pessoas, aumentando ainda mais o seu número de clientes.

Analisando os aspectos e impactos informados, nota se que estão intrinsicamente relacionados com os argumentos a favor da Responsabilidade Social argumentados por Keith Davis apud Montana; Charnov (2001), apresentados na pesquisa bibliográfica exposta acima no presente artigo. 


\section{CONSIDERAÇÕES FINAIS}

O presente artigo expõe algumas das inúmeras definições sobre a Estratégia, que em poucas palavras pode se concluir, que é um plano de ação, direcionado de forma inteligente, onde se tira proveito das situações vantajosas, e tem como finalidade alcançar os objetivos pré-definidos da melhor maneira possível, contribuindo para a competitividade da organização. Com base no material apresentado e em diversas pesquisas, as quais não foram todas expostas, a Responsabilidade Social, que num primeiro momento era vista pelas empresas apenas como um meio de retribuir a sociedade os possíveis danos causados como consequência de sua atuação, passou a ser vista também como um diferencial competitivo, tendo em vista que a sociedade passou a fazer maiores pressões e exigências das empresas, e muitos consumidores passaram a optar pelos produtos e/ou serviços das organizações que estão voltadas para as questões de aspecto social, o que tem feito com que as organizações praticantes da Responsabilidade Social, obtivessem ganho de imagem, fato este que indiretamente tem tornado a Responsabilidade Social um diferencial competitivo para as empresas, impactando na maneira de se pensar a estratégia.

\section{REFERÊNCIAS}

ABNT NBR ISO 26000:2010.

ALENCASTRO, Mario Sergio Cunha. Ética empresarial na pratica: liderança e responsabilidade corporativa. ed. Curitiba: Intersaberes, 2013.

ANSOFF, H. Igor. Estratégia empresarial. ed. São Paulo: McGraw-Hill do Brasil, 1977.

BERTONCELLO, Silvio Luiz Tadeu; JUNIOR, Joao Chang. A importância da Responsabilidade Social Corporativa como fator de diferenciação. 2007. $7 \mathrm{f}$. Artigo Revista. FACOM - ํo 17 - 1ㅇs semestre de 2007 
BORGER, Fernanda Gabriela Responsabilidade Social: Efeitos da atuação social na dinâmica empresarial. Tese (Doutorado) - Universidade de São Paulo. São Paulo, 2001.

CERTO, Samuel; PETER, J. Paul. Administração estratégica. ed. São Paulo: Makron Books, 1993.

CHIAVENATO, Idalberto, SAPIRO, Arão. Planejamento Estratégico: Fundamentos e Aplicações - Da intenção aos resultados. 2. ed. Rio de Janeiro: Elsevier, 2009.

CLAUSEWITZ, Carl Von. Da Guerra. São Paulo: WMF Martins Fontes, 1996

ESTEVES, Sérgio A. P. org. O Dragão e a Borboleta: Sustentabilidade e Responsabilidade Social nos Negócios. Axis Mundi Editora Ltda, 2000.

GHEMAWAT, Pankaj. A Estratégia e o Cenário de Negócios. Porto Alegre: Ed. Bookman, 2000.

INSTITUTO ETHOS. Sobre o instituto - visão. Disponível em<https://www3.ethos.org.br/conteudo/sobre-o-instituto > Acesso em: 10 out. 2017.

KREITLON, Maria Priscilla. A Ética nas Relações entre Empresas e Sociedade: Fundamentos Teóricos da Responsabilidade Social Empresarial. 2004. 13f. Artigo. XXVIII ENANPAD, Curitiba, 2004.

LOBATO, David Menezes. Estratégia de empresas. 3. ed. Rio de Janeiro: Editora FGV,

MALUF, Rosangela; SAMPAIO, Danilo de Oliveira. Marketing II. ed. Belo Horizonte: Fead, 2010.

MAQUIAVEL, Nicolau. O Príncipe. São Paulo: Martins Fontes, 1999.

MINTZBERG, Henry; AHLSTRAND, Bruce; LAMPEL, Joseph. Safári de estratégia: um roteiro pela selva do planejamento estratégico. ed. Porto Alegre: Bookman, 2000. 
MONTGOMERY, Cynthia A.; PORTER, Michael E. Estratégia: A Busca da Vantagem Competitiva. ed. Rio de Janeiro: Campus, 1998.

MONTANA, Patrick J; Charnov, Bruce H. Administração. São Paulo: Saraiva,2001.

OLIVEIRA, Djalma de Pinho Rebouças de. Estratégia empresarial: uma abordagem empreendedora. 2. ed. São Paulo: Atlas, 1991.

OLIVEIRA, Ana Claudia Sá. Aplicação do Balanced Scoredcard à gestão estratégica do Instituto Federal de Educação, Ciência e Tecnologia da Bahia. Dissertação. 107 p. Salvador: Universidade Federal da Bahia, 2014

PÁDUA, Elizabete Matallo Marchesini de. Metodologia da pesquisa: abordagem teórico-prática. 15. ed. São Paulo: Papirus, 2009. 127 p.

PINTO, Luiz Fernando da Silva. Gestao-cidada: Ações estratégicas para a participação social no Brasil. ed. Rio de Janeiro: FGV, 2002.

PORTER, Michael E. Competição = On competition: estratégias competitivas essenciais. 12.ed Rio de Janeiro: Campus, 1999. 515 p.

SOUZA, Claudio Alexandre de. "DNA" da Responsabilidade Social Empresarial. Artigo. 7- Doutrina Nacional. vol. 2 n. 4 Foz do Iguaçu: Revista Direito à Sustentabilidade

TZU, Sun. A arte da Guerra. ed.2 São Paulo: Ciranda Cultural, 2008.

WHITTINGTON, Richard. O que é estratégia. ed. São Paulo: Pioneira Thomson Learning, 2002

Enviado: Agosto, 2018.

Aprovado: Outubro, 2018. 